\title{
Measuring Enterprise Mutual Information Based on the Helix Model
}

\author{
Wei Wang, Shanghai Academy of Development and Reform, School of Economics of Fudan University, China \\ Xucheng Huang, Shanghai Lixin University of Accounting and Finance, China* \\ Shougui Luo, Shanghai Jiao Tong University, China*
}

\begin{abstract}
In the context of digital transformation, this emerging technology input creates powerful digital capabilities. Despite of the long distance, the enterprises cooperate more closely through wireless networks in digital space than ever before. Thus, the digital technology has fundamentally changed the total performance of Shanghai-based enterprises over the 2016-2020 period. This paper creatively explores the influence mechanism of digital transformation through the mutual information measures on enterprise development. The authors use the helix model to the interactive relationship transformation among location, industry, vertical industrial linkages, and cooperative partners for the enterprises, which are based on the degree of link among the quadruple variables. It shows transformation of enterprise structure and innovation and performance by measuring the mutual information. As a result, this paper reveals transformation of the total performance with emerging technologies. In addition, it shows the transformation of industrial and spatial structure in Shanghai by comparing other countries.
\end{abstract}

\section{KEYWORDS}

Cooperative, Digital, Helix Model, Industry, Location, Mutual Information, Physical Location, Vertical Industrial Linkages

\section{INTRODUCTION}

\subsection{The Digital Technology Impact}

Due to epidemic spreading of COVID-19, many organizations or enterprises change their business management online instead of face to face mode. Vaishnav analyzed for screening COVID-19 in framework review (Vaishnav et al., 2021). Online mode can avoid epidemic spreading of the contagious virus, save some travel and traffic, hence reduce usage of petrol and air pollution; which is important for sustainable development of environment and economy especial for enterprises performance in the long run. In recent ten years, the digital technology is enhancing the innovation and productivity of enterprises than ever before. Information and communication technologies (ICTs) have become ubiquitous to many aspects. For example, an increasing number of enterprises are migrating their business processes to the web, which form the so-called online network communities (e.g., Alibaba, Wechat and Jingdong market). Many patients are used to consulting the Internet when they are not 
feeling well. Suli examined patients' decisions to use online and offline health services by integrating the extended framework and the halo effect (Suli et al., 2021). With the development of Web 2.0, user generated content in social media platforms has become a major source of information dissemination and retrieval (Huang et al., 2020). Co-evolution between the organizations and the operational mechanism of digital innovation, in turn, affects the organization total performance or productivity remotely from each other. Physical obstacle is reduced by using information resources management. Thus, to measure how is total performance of enterprises has its significant meaning in the digital impact on the physical boundaries of upstream suppliers, downstream agents and cooperation partners. Also, smart solutions to optimize the infrastructural communication are still needed to be improved.

\subsection{The Triple Helix theory and Its Applications}

Etzkowitz and Leydesdorff introduced the triple helix model into the innovation system of a knowledge economy to analyze the interrelationships among university, industry and government, believing that the innovation system was characterized by overlaps among these three sectors. Contact among the three parties is an important factor in the production and dissemination of knowledge. The three participants interact with one another as knowledge is transformed into productivity, thus enhancing the innovation spiral (Etzkowitz et al., 1995; Nu et al., 2009; Tu et al., 2006). Leydesdorff utilized quantitative methods to measure the relationships among the university, industry and government sectors in the fields of networks, academic publications and patents (Leydesdorff et al., 2000; Leydesdorff et al., 2002; Leydesdorff et al., 2006). Furthermore, Storper employed a Venn diagram to introduce the "three-in-one" theory, which posits that the relationships among technologies, organizations and regions are overlapping, resulting in a new environment based on relationship density (Storper et al., 1997). In the "three-in-one" theory, Leydesdorff and Michael Fritsch described geography, technology and organizations as three independent sources of variation that overlap with one another and reduce uncertainty, in addition to explaining basic knowledge allocation. Therefore, these authors considered the relationships among geography, technology and organizations as the knowledge basis for research regarding the triple helix model (Leydesdorffet al., 2006). Leydesdorff measured knowledge foundations in Holland, Germany and Hungary, which led to the instructive conclusion that middle-tech knowledge is more important to regional knowledge accumulation than high-tech knowledge because high-tech knowledge tends to decompose the knowledge foundation (Leydesdorffet al.,2011; Theil et al., 1972). Compared with previous measures in economic knowledge theory, the method is innovative not only as a methodology but also in terms of its analytical tool, and it can explain knowledge configuration and the evolution of knowledge systems. For global optimization, Dhiman employed a novel bio-inspired based heuristic technique for engineering applications and industrial engineering problems with intelligence techniques (Dhiman et al., 2017; Dhiman et al., 2018; Dhiman et al., 2019). Kumar used another fuzzy number for Fuzzy Optimization (Kumar et al., 2021). Research on the triple helix in theory is advancing; according to systems theory, the three subsystems interact with and promote one another, leading to the dynamic evolution of the system (Fig. 1).

Compared with studies of the triple helix model in other countries, researchers in China have made considerable achievements. Fang firstly introduced the triple helix and emphatically discussed its application in public policy(Fanget al., 2003). Qi analyzed the evolution of innovative strategies based on the triple helix in China(Qiet al., 2007). Zhou set forth the university, public and government model consisting of sustainable triple helix development(Zhouet al., 2006; Zhouet al., 2008); he also proposed an innovative model of the triple field and triple cycle based on a nonlinear model. In an extension of that model, Zhou analyzed co-evolution between the organization and the operational mechanism of regional innovation and noted that the organization determines the operational mechanism and that the operational mechanism, in turn, affects the organization(Zhouet al., 2010). Cai, Wang and Li analyzed the model's application and thought it to be more persuasive for regional innovation ina knowledge economy(Caiet al., 2010). Wang presented the triple helix model that included the 


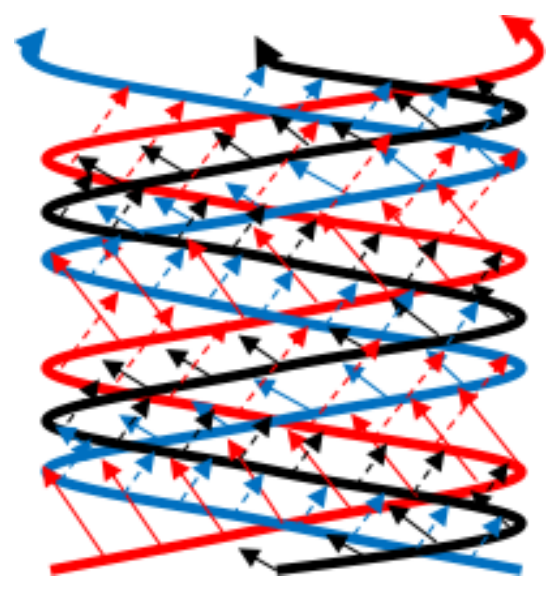

TH algorithm(Wanget al., 2006). Pan set forth aknowledge transfer framework for the triple helix model(Panet al., 2009; Panet al., 2008). In regional development, Qi and Wu analyzed innovation strategy in China since 1949 using the triple helix model, and posited that government innovation, university innovation, and industry innovation will become the main trends in innovation in China(Qiet al., 2007). Wang conducted research on the Jiangsu Industrial Park and noted that the university is the creative source in the city of Nanjing, industry is the incubator for the city, and the government is the planner and promoter of the city(Wanget al., 2008). Liu and Peng conducted research on an entrepreneurial university in China based on the triple helix model(Liuet al., 2007). Zhang and Chi discussed the management of an entrepreneurial university using the triple helix model(Zhanget al., 2010). Niu proposed the measurement of economic knowledge in various provinces in China by using the entropy and cluster method that is based on the relationships among technology, organization and geography (Niuet al., 2009).

\subsection{Research on the Location and Vertical Industrial Linkage}

The study of industrial location and vertical industrial linkages is an important foundational element of our thesis. Liu used the Gini coefficient and location entropy on a pesticide industry cluster and showed a positive correlation between the pesticide industry cluster and industrial growth in China(Liuet al.,2010). Shao performed an analysis based on changes in thel ocation of firms in the wheat industry in Henan province employing a theory of industrial location with a production function model(Shaoet al.,2010). Ji constructed an industry-international location chain model and an industry location matrix (Jiet al.,2007). Wei used the location entropy and gray forecasting model to analyze and discuss the development of the main industry in Guangxi and predicted its future trends, setting forth a strategy for Guangxi industry in the process(Weiet al.,2012). Luo analyzed the spatial correlations between the multimedia industry and location(Luoet al.,2008). Wang used Chinese panel data and calculated the location entropy between the service and manufacturing industries and then tested the interactive effect of the two through the simultaneous equations(Wanget al.,2012). Zhou studied the influence of industry clusters and vertical spillovers in related industries at the micro enterprise level, revealing a positive effect on the efficiency of enterprises in the industrial cluster and a promoting effect on vertical spillovers(Zhouet al.,2011).

\subsection{Research on the Chain Value and Vertical Industrial Linkage}

Gereffi proposed that the global value chain $(\mathrm{GVC})$ in the global economy, when viewed from the top down, consists of the autonomous management of the GVC (with a focus on leading companies) that 
has five types of value chain structures (market, modular, relational, captive, multilayer)(Gereffiet al., 2011). The bottom-up view consists of how to upgrade from low value added activities to higher value-added activities, such as the successful industrial upgrading cases of China and Mexico. Chen noted that information sharing between downstream and upstream is beneficial to the GVC(Chenet al., 2012). Zou explained technical capabilities in the GVC to reveal the internal operations of a company, including acquisition capabilities, absorptive capabilities, and innovation abilities(Zouet al., 2010). There are decisive factors such as the upstream and downstream industry characteristics, leading enterprises, and local enterprises for enterprises seeking industrial upgrades. Haakonsson used the high-tech pharmaceutical industry as an example; in that industry, the value chain is divided into the following three types: brand products driven by producers, high-quality products driven by consumers and low-value products driven by no particular party(Haakonssonet al., 2009). He believed that multi-national corporations comprised the pharmaceutical industry across the vertical chain, and these companies maintain high sales in the country with very little investment in the greater market. However, the pharmaceutical industry become more global as the World Tourism Organization(WTO) expanded its coverage. Beltramello studied the export performance of upstream and downstream enterprises in the value chain and of enterprises producing intermediate products, in particular in his search for a method to determine enterprise competitiveness(Beltramelloet al., 2012).

Addressing vertical industrial linkages with enterprise data from Spain during the 1990-2000 period, Jabbour analyzed the effects of horizontal and vertical foreign direct investment (FDI) spillovers on technical upgrades and found that the effects of spillovers are determined by the differences between domestic and foreign technologies(Jabbouret al., 2007). In addition, the horizontal spillover effect is not obvious because the domestic and foreign enterprises are the same industry competitors; however, vertical spillovers can play a positive role because foreign enterprises hope that their local suppliers in the vertical industrial linkage and the manufacturers in vertical forward linkages will improve their technical levels. Thus, research in vertical correlation is more important for industrial upgrades. Sergio used the regression method to verify multinational service enterprises by analyzing vertical forward linkages and vertical backward linkages to determine how to influence local manufacturing enterprise productivity(Mariotti et al., 2013). On the one hand, the enterprise influences local suppliers through growing demand; on the other hand, the enterprise encourages local consumption through participation in the local service industry. Inge showed how the retailer IKEA used various methods in the consumer-driven industry chain to promote the technological upgrade of upstream suppliers(Ivarssony et al., 2011). Lina used a two-layer oligopoly model to explain the relations between multi-national corporations and local suppliers with respect to influencing backward linkages(Ping et al.,2007). Kozo found that unobserved determining factors of vertical relationships in Japan can explain changes in backward linkages(Kiyota et al., 2008). Bitzer analyzed the horizontal and vertical spillovers of multi-national corporations using industry level data from OECD countries and concluded that all countries have backward linkage spillovers but that the spillover effects of backward linkages from central and eastern Europe an countries are stronger than those of OECD countries(Bitzeret al., 2008). Liunoted positive and negative effects on Chinese enterprises by means of horizontal and vertical spillovers(Liuet al., 2009). Duch studied the influence of European mergers and analyzed the effects of the vertical chain on labor distribution by using the industrial organization and location(Duchet al.,2005). Wang used Canadian industry to demonstrate how FDI affects total factor productivity (TFP) by using forward and backward industry relevance and noted that TFP can be improved by increasing the absorptive capacities of enterprises(Wanget al.,2010).In the research enterprise, FDI's effect on TFP through the industrial chain is not particularly apparent. However, imports can improve TFP.

\subsection{Summary}

Recently, the triple helix model has been increasingly applied to interactions among the three subsystems in innovation such as industry, university and government. The interpretation of the 
physical meaning of mutual information of the helix model indicate interactions or synergy level. Higher mutual information means the deeper synergy among industry, university and government. However, there is few research on the interactions degree among location, industry and vertical industrial linkages factors in the digital space by using the triple helix. The influence of these key factors is complex and nonlinear. In return, the degree of evolution of digital industries will affect the changes of location structure, industry, vertical correlation and partners. The evolution process of productivity and the changes of the above key factors are intertwined and influenced to achieve coordinated development and maintain a stable state within a certain equilibrium range. Especially, there is a need to measure the total performance with the influence of digital technologies in frameworks. The authors collected enterprise information about location, industry, and enterprises along the industry chain in Shanghai and other countries. Also, there is a need to extend to a quadruple model by using cooperative partners as the fourth variable. Business cooperation means that different cooperative partners share their responsibilities through contracts, share the advantages of both parties, jointly develop products or markets, share risks and interests, so as to maximize the overall interests. This study will reveal Shanghai's enterprise cross-field integrated performance or productivity in the digital network during the recent transformation of its industrial structure and spatial structure adjustment by using the helix model.

\section{METHOD}

\subsection{The Basic Helix Model (Leydesdorffet al.,2006)}

Shannon defined a measure of uncertainty (entropy) in a probabilistic distribution of variable $\mathrm{x}$ : where the basis of the logarithm is 2 , the value is expressed in bits of information.

$$
H_{x}=-\sum_{x} p_{x} \log _{2} P x
$$

Analogously, this uncertainty is the sum of the uncertainty in the two dimensions reduced by their co-variation:

$$
H_{x y}=-\sum x \sum y P_{x y} \log _{2} P_{x y}
$$

When there are two dimensions, the uncertainty in the two potentially interacting dimensions ( $\mathrm{x}$ and $\mathrm{y}$ ) can be reduced by common entropy $\left(\mathrm{H}_{\mathrm{XY}}\right)$. Mutual information or transmission $\left(\mathrm{T}_{\mathrm{XY}}\right)$ is used, which measures the performance of synergy and captures the reduction of uncertainty as follows:

$$
T_{x y}=\left(H_{x}+H_{y}\right)-H_{x y}
$$

In the limiting casein $=0$ which distributions $\mathrm{x}$ and $\mathrm{y}$ are completely independent, then $\mathrm{T}_{\mathrm{XY}}=0$ or $\mathrm{H}_{\mathrm{X}}+\mathrm{H}_{\mathrm{Y}}=\mathrm{H}_{\mathrm{XY}}$. In all other cases, $\mathrm{T}_{\mathrm{XY}}>=0$ or $\mathrm{H}_{\mathrm{XY}}<=\left(\mathrm{H}_{\mathrm{X}}+\mathrm{H}_{\mathrm{Y}}\right)$. Note that $\mathrm{T}_{\mathrm{XY}}$ in two dimensions represents how the system affects the decline in uncertainty. High positive value $T_{X Y}$ indicates a better fit because of the relationship of the two variances( $x$ and $y$ ). Thus, $T_{X Y}$ increases as the correlation between $\mathrm{x}$ and $\mathrm{y}$ increases. The increasing $\mathrm{T}_{\mathrm{XY}}$ indicate more deeper relationship in $\mathrm{x}$ and $\mathrm{y}$.

Abramson showed that mutual information in three dimensions can be derived as (Abramsonet al., 1963): 


$$
\begin{aligned}
T_{x y z} & =\sum x y z P_{x y z} \log \left(\frac{P_{x y} P_{x z} P_{y z}}{P_{x} P_{y} P_{z} P_{x y z}}\right. \\
T_{x y z} & =\left(H_{x}+H_{y}+H_{z}\right)-H_{x y}-H_{z y}-H_{x z}+H_{x y z}
\end{aligned}
$$

Note that the uncertainty of the variables measured in each of the interacting systems ( $x$ and $\mathrm{y}, \mathrm{y}$ and $\mathrm{z}$, and $\mathrm{x}$ and $\mathrm{z}$ ) is reduced at the system level by the relations between them, but the threedimensional uncertainty positively adds to the prevailing uncertainty. Because the signs are altered, the three-dimensional transmission can become negative. As noted above, this reduction of the uncertainty by the negative transmission is a result of the network configuration of bi-lateral relations that develops without central coordination and symmetry (Figure 2). Thus, $\mathrm{T}_{\mathrm{XYZ}}$ is used as a measure of the reduction of the uncertainty at system levels, where a high negative value indicates a better fit.

To extended this analysis, because the last sign of plus or minus will change alternatively in odd $(2 \mathrm{~N}+1)$ and even dimensions $(2 \mathrm{~N})$, the interpretation of $\mathrm{T}$ is thus the opposite. In odd dimensions $(2 \mathrm{~N}+1)$, high negative value indicates a better fit. In even dimensions $(2 \mathrm{~N})$, high positive value indicates a better fit. The mutual information can be considered as a measure of the 'synergy' degree which a regional economy has become knowledge-based in the digital space.

Figure 2. Relations between probabilistic entropy $(H)$, transmission $(T)$
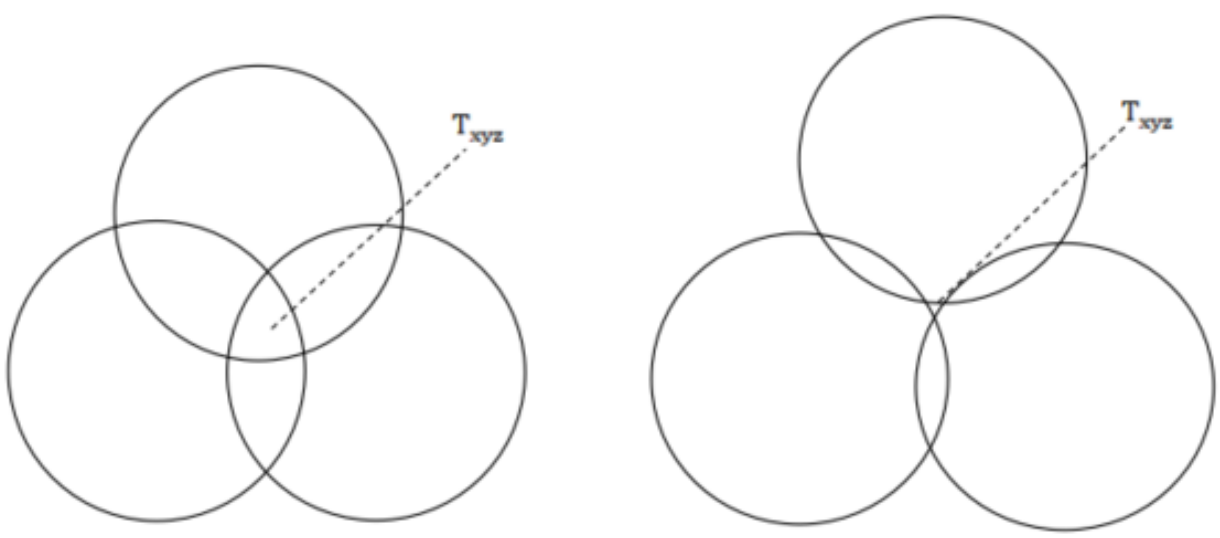

Source: Leydesdorff, L. The Measurement and Evaluation of Triple Helix Relations among Universities, Industries and Governments.

(a) Three subsystems with a center of coordination, $\mathrm{T}_{\mathrm{XYZ}}>0$; (b) Three subsystems with no center of integration, $\mathrm{T}_{\mathrm{XYZ}}<0$

\subsection{The Advanced Model with Quadruple Variables: Location, Industry, Vertical Industrial Linkages and Cooperative Partners}

The emergence of emerging technologies has not only changed the physical location of enterprises but also the physical location of upstream suppliers, downstream agents and cooperation partners which 
has fundamentally changed physical boundaries of enterprises and promote their total performance significantly in the digital space. Enterprises interact with each other by more digital tools (e.g., big data, cloud computing, block chain, and so on) instead of the traditional way. The long distant hinder in the physical space is removed by their increasing synergy in digital space with technologies application. According to location theory, enterprises' distributions are affected by differentiated land rent; thus, the city center, suburbs and their transition areas have different influences on different industries. For example, high value added modern service industries may be located in the central business district, whereas low value added enterprises covering large areas may be located in the outer suburb district. Industries and locations have a vertical relationship. For example, an enterprise may be located in the city center and may also be located in the suburbs and outer-suburbs, depending on what type of industry it belongs to and on the location of its vertical upstream and vertical downstream enterprises. Vertical industrial linkages will directly affect the production efficiency of upstream and downstream enterprises. Moreover, based on the advantages of main business, it can enter the relevant extended industries upstream and downstream of the industry and expand the profit space. In fact, location, industry and vertical industrial linkages can be considered as the holy trinity of regional development. This holy trinity should not be studied as an aggregate of its constitutive elements but instead in terms of the relations among these elements. These relations shape regional economics and reflect the orderly degree of the layout of an industrial space. If a company is in developed countries, order will be reached at a higher level with long-term adjustments through free competition. However, market development is not mature in China and is controlled by the government, and changes in the orderly degree over the short term may therefore not be obvious. This paper shows how relationships are changing in Shanghai by measuring the mutual information among the location, industry and vertical linkages. The three distributions can be used to specify the configurational information. In addition, The authors employ enterprise's cooperative partners as the fourth nominal variable. Cooperative partner establish the basis of mutual trust and adopt a long-term cooperative relationship of sharing risks and benefits. For areas where enterprises are not good at, form alliances with partners to promote chemical reactions through ecological synergy. Partners from different regions will affect the degree of cooperation integration. Due to the convenience of digital communication methods, the opportunities for both sides to meet, communicate and cooperate with each other greatly increase, and the frequency of cooperative innovation increases, which greatly improves the success rate of innovation achievements and the communication cost is also greatly reduced. Thus, triple and quadruple entropy can be used as a measure of the reduction of uncertainty

Table 1. The classification of locations in Shanghai

\begin{tabular}{|c|c|c|c|c|c|c|c|}
\hline Type of district & district & Postcode & $\begin{array}{c}\text { Classification } \\
\text { number }\end{array}$ & $\begin{array}{l}\text { Type of } \\
\text { district }\end{array}$ & district & Postcode & $\begin{array}{c}\text { Classification } \\
\text { number }\end{array}$ \\
\hline \multirow[t]{3}{*}{ Core } & Huangpu & 310101 & 1 & \multirow[t]{3}{*}{ Suburbs } & Baoshan & 310113 & 11 \\
\hline & Jingan & 310106 & 2 & & Jiading & 310114 & 12 \\
\hline & Luwan & 310103 & 3 & & Minghang & 310112 & 13 \\
\hline \multirow[t]{7}{*}{ Center } & Hongkou & 310109 & 4 & \multirow{5}{*}{$\begin{array}{l}\text { Outer- } \\
\text { Suburbs }\end{array}$} & Chongming & 310230 & 14 \\
\hline & Pudong & 310115 & 5 & & Fenxian & 310120 & 15 \\
\hline & Putuo & 310107 & 6 & & Jinshan & 310116 & 16 \\
\hline & Xuhui & 310104 & 7 & & Qingpu & 310118 & 17 \\
\hline & Yangpu & 310110 & 8 & & Songjiang & 310117 & 18 \\
\hline & Zhabei & 310108 & 9 & & & & \\
\hline & Changing & 310105 & 10 & & & & \\
\hline
\end{tabular}


generated by the synergy among the location, industry, vertical linkages and cooperative partners cross diverse sites. This above measure represents the enterprise's total performance in the digital space than the physical space.

With respect to location, the areas of Shanghai are classified into core, center, suburbs and outersuburbs in Table 1.The location variable is denoted by $\mathrm{L}$.

Following Leydesdorff, the entire industry is classified into high-tech manufacturing, mediumtech manufacturing, knowledge intensive sectors, traditional service and other industries and thus provides us with the technological classes of firms. The industry variable is denoted by I.

Enterprises in the vertical upstream of the industry chain may be located in the same region in which the center enterprises are located, other regions in the city, other cities in the country, or abroad. Simultaneously, enterprises or retailers in the vertical downstream of the industry chain may

Table 2. The classification of technical industry

\begin{tabular}{|c|c|c|}
\hline Type & code & $\begin{array}{c}\text { Classification } \\
\text { number }\end{array}$ \\
\hline $\begin{array}{l}\text { High-tech } \\
\text { Manufacturing }\end{array}$ & $\begin{array}{l}27 \text { pharmaceutical manufacturing industry } \\
40 \text { communication equipment, computers and other electronic equipment } \\
\text { manufacturing industry } \\
41 \text { instrumentation and culture, office machinery manufacturing }\end{array}$ & $\begin{array}{l}1 \\
2 \\
3\end{array}$ \\
\hline $\begin{array}{l}\text { Medium-tech } \\
\text { Manufacturing }\end{array}$ & $\begin{array}{l}26 \text { chemical materials and chemical products manufacturing } \\
39 \text { electrical machinery and equipment manufacturing industry } \\
37 \text { transportation equipment manufacturing industry } \\
35 \text { general equipment manufacturing industry } \\
28 \text { chemical fiber manufacturing industry } \\
36 \text { special equipment manufacturing industry }\end{array}$ & $\begin{array}{l}4 \\
5 \\
6 \\
7 \\
8 \\
9\end{array}$ \\
\hline $\begin{array}{l}\text { Knowledge - } \\
\text { intensive }\end{array}$ & $\begin{array}{l}\text { F transport, storage and postal industry } \\
\text { G information transmission, computer service and software industry } \\
\text { J financial industry } \\
\text { K real estate } \\
\text { L leasing and business services } \\
\text { M scientific research, technical services and geological prospecting industry } \\
\mathrm{N} \text { water conservancy, environmental and public facilities management industry } \\
\text { P education } \\
\text { Q health, social security and social welfare } \\
\text { R culture, sports and entertainment } \\
\text { S public management and social organization }\end{array}$ & $\begin{array}{l}10 \\
11 \\
12 \\
13 \\
14 \\
15 \\
16 \\
17 \\
18 \\
19 \\
20\end{array}$ \\
\hline $\begin{array}{l}\text { Traditional } \\
\text { services }\end{array}$ & $\begin{array}{l}\text { H wholesale and retail } \\
\text { I accommodation and catering industry } \\
\text { O resident services and other services }\end{array}$ & $\begin{array}{l}21 \\
22 \\
23\end{array}$ \\
\hline other & others & 24 \\
\hline
\end{tabular}

be located in the same region in which the leading enterprises are located, in other regions in the city, other cities in the country, or abroad. Thus, vertical industrial linkage variable that link downstream and downstream enterprises are classified into 16 types in Table 3. The vertical linkage variable is denoted by V.

The authors define the relationship of Location-Industry-Vertical industrial linkage

$T_{L I V}=\left(H_{L}+H_{I}+H_{V}\right)-H_{L I}-H_{L V}-H_{I V}+H_{L I V}$ 
Table 3. Type of vertical industrial linkages

\begin{tabular}{|c|c|c|c|c|}
\hline $\begin{array}{l}\text { Upstream suppliers( } \\
\text { main raw materials, semi- } \\
\text { finished products suppliers } \\
\text { from the region below) }\end{array}$ & Postcode & $\begin{array}{l}\text { Downstream agents } \\
\text { (main products, services } \\
\text { to the regions below) }\end{array}$ & Postcode & $\begin{array}{c}\text { Classification } \\
\text { number }\end{array}$ \\
\hline local region & uncertain1 & local region & uncertain1 & 1 \\
\hline local region & uncertain1 & other regions in the city & uncertain2 & 2 \\
\hline local region & uncertain1 & other cities in the country & 860000 & 3 \\
\hline local region & uncertain1 & abroad & 888888 & 4 \\
\hline other regions in the city & uncertain2 & local region & uncertain1 & 5 \\
\hline other regions in the city & uncertain2 & other regions in the city & uncertain2 & 6 \\
\hline other regions in the city & uncertain2 & other cities in the country & 860000 & 7 \\
\hline other regions in the city & uncertain2 & abroad & 888888 & 8 \\
\hline other cities in the country & 860000 & local region & uncertain1 & 9 \\
\hline other cities in the country & 860000 & other regions in the city & uncertain2 & 10 \\
\hline other cities in the country & 860000 & other cities in the country & 860000 & 11 \\
\hline other cities in the country & 860000 & abroad & 888888 & 12 \\
\hline abroad & 888888 & local region & uncertain1 & 13 \\
\hline abroad & 888888 & other regions in the city & uncertain2 & 14 \\
\hline abroad & 888888 & other cities in the country & 860000 & 15 \\
\hline abroad & 888888 & abroad & 888888 & 16 \\
\hline
\end{tabular}

Note: The uncertain 1 means the firm and its upstream or downstream partners are from the same region whatever their postcode. The uncertain2 means the firm and its upstream or downstream partners aren't from the same region in Shanghai

Where $\mathrm{H}_{\mathrm{L}}$ is location entropy, $\mathrm{H}_{\mathrm{I}}$ is industry entropy, $\mathrm{H}_{\mathrm{V}}$ is vertical industrial linkage entropy, $\mathrm{H}_{\mathrm{LV}}$ is the $2 \mathrm{D}$ joint distribution entropy of location and industry, $\mathrm{H}_{\mathrm{LV}}$ is the $2 \mathrm{D}$ joint distribution entropy of location and vertical industrial linkages, $\mathrm{H}_{\mathrm{IV}}$ is $2 \mathrm{D}$ joint distribution entropy of industry and vertical industrial linkages, $\mathrm{H}_{\mathrm{LIV}}$ is $3 \mathrm{D}$ joint distribution entropy of location, industry and vertical industrial linkages, and TLIV is the3Dtransmission of location, industry and vertical industrial linkages.

In addition, The authors used the fourth variable $C$ proxy for the location in which every company's cooperative partners locate (see Table 4). Thus, the synergy for the relations of Location, Industry, Vertical industrial linkages and Cooperative partners can be expressed as,

$T_{L I V C}=\left(H_{L}+H_{I}+H_{V}+H_{C}\right)-H_{L I}-H_{L V}-H_{I V}-H_{L C}-H_{V C}-H_{I C}+H_{L I V}+H_{C I V}+H_{L C V}+H_{L I C}-H_{L I V C}$

\section{DATA, CALCULATION PROCESS AND RESULTS}

\subsection{Data}

The authors have collected technical enterprise data for more than 20,000 registered enterprises(including micro-information)from 18 districts in Shanghai for four years over the 2016-2020 period covering enterprise locations determined by postal codes that provides a fine-grained map of regions, the industry code in which enterprises operate from Table 2 the second column, the upstream region code 
in which the main raw materials/semi-finished products or services suppliers originate from Table 3 the second column, the downstream region code to which the main products or services are delivered from Table 3 the fourth column, and the region code to which cooperative partners are from Table 4 the second column. In order to convert above actual data into probability distribution, we map raw postcode or code data in Table 5 to classification number in Table 6 based on the mapping Table1-4. Then, The mapped variables ( $\mathrm{L}, \mathrm{I}, \mathrm{U}, \mathrm{D}, \mathrm{C})$ in Table 6 are considered as nominal variables which be ready for calculating entropy. Thus, the raw or actual data can be seen in Table 5 , the corresponding probability distributions that the authors need in algorithm can be shaped in Table 6 .

Table 4. The region from which cooperative partners are

\begin{tabular}{|l|l|l|}
\hline every enterprises' cooperative partners locate in region & \multicolumn{1}{|c|}{ Postcode } & \multicolumn{1}{|c|}{ Classification number } \\
\hline local region & uncertain1 & 1 \\
\hline other regions in the city & uncertain2 & 2 \\
\hline other cities in the country & 860000 & 3 \\
\hline abroad & 888888 & 4 \\
\hline
\end{tabular}

Note: The uncertain 1 means the firm and its cooperative partners are from the same region whatever their postcode. The uncertain2 means the firm and its cooperative partners aren't from the same region in Shanghai

Table 5. The region from which cooperative partners are

\begin{tabular}{|l|l|l|l|l|l|}
\hline \multicolumn{1}{|c|}{ Firm } & \multicolumn{1}{|c|}{$\begin{array}{c}\text { Location } \\
\text { Postcode }\end{array}$} & \multicolumn{1}{c|}{$\begin{array}{c}\text { Industry } \\
\text { code }\end{array}$} & \multicolumn{1}{c|}{$\begin{array}{c}\text { Upstream } \\
\text { Postcode }\end{array}$} & \multicolumn{1}{c|}{$\begin{array}{c}\text { Downstream } \\
\text { Postcode }\end{array}$} & \multicolumn{1}{c|}{$\begin{array}{c}\text { Cooperators } \\
\text { Postcode }\end{array}$} \\
\hline Firm-1 & 310230 & F & 888888 & 860000 & 888888 \\
\hline Firm-2 & 310118 & G & 860000 & 888888 & 310118 \\
\hline Firm-3 & 310119 & M & 310120 & 310118 & 860000 \\
\hline Firm-4 & 310120 & P & 310120 & 310120 & 310120 \\
\hline$\ldots$. & $\ldots$. & $\ldots$ & $\ldots$ & $\ldots$ & $\ldots$ \\
\hline Firm-N & $\ldots$. & $\ldots$. & $\ldots$. & $\ldots$ & $\ldots$ \\
\hline
\end{tabular}

Table 6. The nominal variables (L, I, U, D, C) response to Table 5 respectively

\begin{tabular}{|l|l|l|l|l|l|}
\hline \multicolumn{1}{|c|}{ Firm } & \multicolumn{1}{c|}{ L } & \multicolumn{1}{c|}{ I } & \multicolumn{1}{c|}{ U } & \multicolumn{1}{c|}{ D } & \multicolumn{1}{c|}{ C } \\
\hline Firm-1 & 14 & 10 & 4 & 3 & 4 \\
\hline Firm-2 & 17 & 11 & 3 & 4 & 1 \\
\hline Firm-3 & 1 & 14 & 1 & 2 & 3 \\
\hline Firm-4 & 8 & 16 & 2 & 2 & 2 \\
\hline$\ldots$ & $\ldots$ & $\ldots$ & $\ldots$ & $\ldots$ & $\ldots$ \\
\hline Firm-N & $\ldots$ & $\ldots$ & $\ldots$ & $\ldots$ & $\ldots$ \\
\hline
\end{tabular}

Note: .... is for other Firms in 20,000 registered enterprises. The values in Table 6 identify different types with no unit.N represent the number about 20,000 registered enterprises. 


\subsection{Calculation Process}

Based on Table 6, the authors get the (L, I, U, D, C) distributions in 20,000 registered enterprises. The variable $\mathrm{L}$ distribution has sequence numbers from L1....L20,000.The variable I distribution has sequence numbers from I1 ....I20,000. The variable U distribution has sequence numbers from U1....U20,000.The variable D distribution has sequence numbers from D1...D20,000.The variable $\mathrm{C}$ distribution has sequence numbers from $\mathrm{C} 1 \ldots . . \mathrm{C} 20,000$. The authors then calculate entropy in 1D, 2D, 3D and 4D by using above sequence numbers (L, I, U, D, C) in Table 6 with no unit. For example, the probabilistic distribution of variable L such as L1....L20,000as inputs is to calculate $\mathrm{H}_{\mathrm{L}}$. The probabilistic distribution of variables (L, I) such as L1....L20,000and I1 ....I20,000as inputs is to calculate $\mathrm{H}_{\mathrm{Lr}}$. The probabilistic distribution of variables (L, I, V) such as L1....L20,000and I1....

Table 7. Entropy in 1D, 2D and 3D,2016-2020 in Shanghai

\begin{tabular}{|c|c|c|c|c|c|c|c|}
\hline \multirow{2}{*}{ Year } & \multicolumn{3}{|c|}{ D1 } & \multicolumn{3}{|c|}{ D2 } & D3 \\
\hline & HI & Hi & Hv & Hli & Hlv & Hiv & Hliv \\
\hline 2016 & 1.655337 & 1.720361 & 2.261327 & 3.336718 & 3.814847 & 3.942823 & 5.446497 \\
\hline 2017 & 1.646669 & 1.774826 & 2.099502 & 3.387624 & 3.673084 & 3.840425 & 5.364304 \\
\hline 2018 & 1.533706 & 1.784182 & 2.189669 & 3.286564 & 3.679561 & 3.936428 & 5.384390 \\
\hline 2019 & 1.575915 & 1.817754 & 2.326755 & 3.360346 & 3.843864 & 4.112197 & 5.582843 \\
\hline 2020 & 1.569905 & 1.7970054 & 2.265721 & 3.329902 & 3.803961 & 4.016984 & 5.499883 \\
\hline
\end{tabular}

Note: D1 is entropy in one dimension, D2 is entropy in two dimensions, and D3 is entropy in three dimensions

Table 8. Mutual information in 2D and 3D,2016-2020 in Shanghai

\begin{tabular}{|l|l|l|l|l|}
\hline \multirow{2}{*}{ Year } & \multicolumn{1}{|c|}{ D2 } & \multicolumn{1}{c|}{ Tiv } & \multicolumn{1}{c|}{ Tliv } \\
\cline { 2 - 5 } & \multicolumn{1}{|c|}{ Tli } & \multicolumn{1}{c|}{ Tlv } & \multicolumn{1}{c|}{ Tiv } & -0.010866 \\
\hline 2016 & 0.038980 & 0.101817 & 0.038865 & -0.015832 \\
\hline 2017 & 0.033871 & 0.073087 & 0.033903 & -0.010604 \\
\hline 2018 & 0.031324 & 0.043814 & 0.037423 & -0.013140 \\
\hline 2019 & 0.033323 & 0.058806 & 0.032312 & -0.018332 \\
\hline 2020 & 0.037008 & 0.031665 & 0.045742 & \\
\hline
\end{tabular}

Table 9. Mutual information in 3D and 4D, 2016-2020 in Shanghai

\begin{tabular}{|l|l|l|l|l|l|}
\hline \multirow{2}{*}{ Year } & \multicolumn{3}{|c|}{ D3 } & \multicolumn{1}{c|}{ D4 } \\
\cline { 2 - 6 } & \multicolumn{1}{|c|}{ Tliv } & \multicolumn{1}{|c|}{ Tciv } & \multicolumn{1}{c|}{ Tlcv } & \multicolumn{1}{c|}{ Tlic } & \multicolumn{1}{c|}{ Tlivc } \\
\hline 2016 & -0.01087 & -0.00169 & 0.059445 & -0.00283 & 0.031884 \\
\hline 2017 & -0.01583 & -0.00057 & 0.034252 & -0.00513 & 0.034174 \\
\hline 2018 & -0.01060 & 0.00538 & 0.004489 & -0.00556 & 0.035303 \\
\hline 2019 & -0.01314 & -0.00059 & 0.015683 & -0.00422 & 0.036907 \\
\hline 2020 & -0.01833 & -0.00069 & 0.030408 & -0.00352 & 0.037907 \\
\hline
\end{tabular}


I20,000and U1....U20,000and D1....D20,000as inputs is to calculate $\mathrm{H}_{\mathrm{LIV}}$. Based on the calculated $\mathrm{H}_{\mathrm{L}}, \mathrm{H}_{\mathrm{I}}, \mathrm{H}_{\mathrm{V}}, \mathrm{H}_{\mathrm{LI}}, \mathrm{H}_{\mathrm{LV}}, \mathrm{H}_{\mathrm{IV}}$ The authors then derive $\mathrm{T}_{\mathrm{LIV}}$ according to formula 6 . In the similar, $\mathrm{T}_{\mathrm{CIV}}$, $\mathrm{T}_{\mathrm{LCV}}, \mathrm{T}_{\mathrm{LIC}}, \mathrm{T}_{\mathrm{LIVC}}$, etc., that can be calculated in the same way.

\subsection{Results}

The authors obtain entropy in $1 \mathrm{D}, 2 \mathrm{D}, 3 \mathrm{D}$ and $4 \mathrm{D}$ by using nominal variables' value (L, I, U, D, C) with no unit. Thus, all the result has no unit.(1) The entropy in $1 \mathrm{D}$ is $\mathrm{H}_{\mathrm{L}}, \mathrm{H}_{\mathrm{I}}, \mathrm{H}_{\mathrm{V}}$ and $\mathrm{H}_{\mathrm{C}}$; (2) the entropy in 2D is $\mathrm{H}_{\mathrm{LI}}, \mathrm{H}_{\mathrm{LV}}, \mathrm{H}_{\mathrm{IV}}, \mathrm{H}_{\mathrm{LC}}, \mathrm{H}_{\mathrm{VC}}, \mathrm{H}_{\mathrm{IC}}$; and (3) the entropy in 3D is $\mathrm{H}_{\mathrm{LIV}}, \mathrm{H}_{\mathrm{CIV}}, \mathrm{H}_{\mathrm{LCV}}, \mathrm{H}_{\mathrm{LIC}}$. (4) the entropy in $4 \mathrm{D}$ is $\mathrm{H}_{\mathrm{LIVC}}$. The resulting reduction of the uncertainty or mutual information can be considered as a measure of the 'synergy' among the three or four dimensions of the extent to which a regional economy has become knowledge-based in the digital space.(Tables7,8 and 9).

In comparison with other developed countries, the authors can collect technical enterprises data from NASDAQ Stock Exchange(USA), London Stock Exchange(UK) and Tokyo Stock Exchange(Japan) easily, which represent the United States of America, the United Kingdom, Japan. In the similar way, the authors calculate TLIVC for the four countries.

From Tables 8-11, the authors conclude as follows:

Table 10. the four-dimensional mutual information in Shanghai in China, USA, UK and Japan

\begin{tabular}{|l|l|l|l|l|}
\hline \multirow{2}{*}{ Year } & \multicolumn{4}{|c|}{ Tlivc } \\
\cline { 2 - 5 } & \multicolumn{1}{|c|}{ China } & \multicolumn{1}{c|}{ USA } & \multicolumn{1}{c|}{ UK } & \multicolumn{1}{c|}{ Japan } \\
\hline 2016 & 0.031884 & 0.034135 & 0.022536 & 0.023087 \\
\hline 2017 & 0.034174 & 0.036981 & 0.023795 & 0.025813 \\
\hline 2018 & 0.035303 & 0.038459 & 0.024961 & 0.026060 \\
\hline 2019 & 0.036907 & 0.038683 & 0.026222 & 0.026314 \\
\hline 2020 & 0.037907 & 0.039478 & 0.027527 & 0.027853 \\
\hline
\end{tabular}

Table 11. the graphical analysis of the four-dimensional mutual information in Shanghai in China,USA, UK and Japan

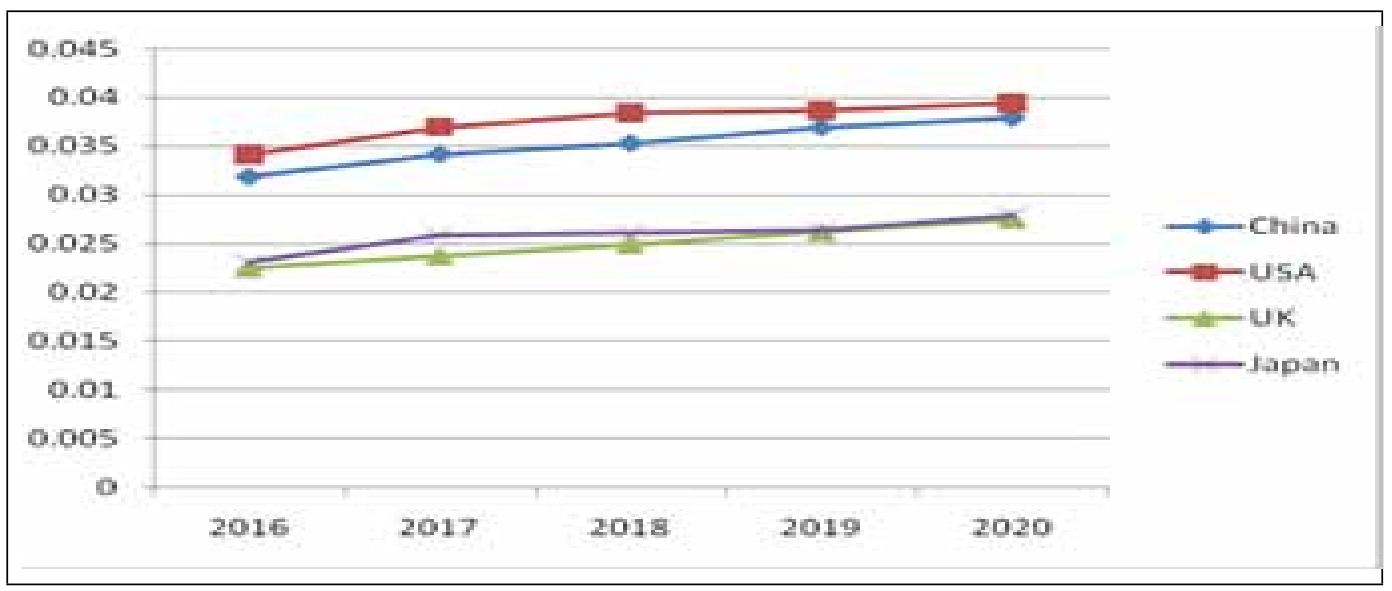


(1) In the change of the 2D transmission, $T_{L I}, T_{L V}$ and $T_{I V}$ were becoming smaller over the 2016-2020 period. According to 2.1, the transmission value in $2 \mathrm{D}$ is always positive, and the greater positive value means better synergy and greater declines in redundancy. Neither of the two interactions shows clearly that the entire industry is changing in terms of location, that the industry upgrade is caused by vertical industrial linkage, or that the location adjustment is caused by vertical industrial linkage. However, in the past four years, small improvements are shown, such as during 2018-2019, when the adjustment of industry in the location was improving, and the upgrade of industry caused by vertical industrial linkages improved. The location adjustment caused by vertical industrial linkages was also improved during 2017-2018.In the change of the 3D transmission, the absolute value $\mathrm{IT}_{\text {LIV }} \mid$ fluctuates over the2016-2020 period. According to 2.1, the larger the absolute value of $I \mathrm{~T}_{\mathrm{LIV}} \mathrm{l}$, the better the interaction is among the location, industry and vertical industrial linkages, which shows that industry structure and location adjustment in Shanghai is moving toward better development. However, fluctuations in 2017 and 2018 demonstrated instability. $I \mathrm{~T}_{\mathrm{LIV}} \mathrm{I}$ is most negative in 2020 , which indicates the best interactive performance because $\mathrm{H}_{\mathrm{L}}, \mathrm{H}_{\mathrm{I}}, \mathrm{H}_{\mathrm{V}}, \mathrm{H}_{\mathrm{LI}}, \mathrm{H}_{\mathrm{LV}}, \mathrm{H}_{\mathrm{IV}}, \mathrm{H}_{\mathrm{LIV}}$ fluctuate at the same time and the reduction of $\mathrm{H}_{\mathrm{LIV}}$ is the main cause of the decrease in IT $\mathrm{T}_{\mathrm{LIV}} \mathrm{I}$.

(2) Comparing 2019 and 2016, the 2D transmission in 2019 was smaller, but the 3D transmission in 2019 was larger. Although interactions between each of the two elements in the triple helix had no obvious improvement, the results show that, the triple interaction was nonetheless improved. This is the meaning of the triple helix. when the three elements are together, there are more complicated activities than on each of the two levels, such that the triple interaction outperforms the other two combined.

(3) In comparing change of the 4D transmission with other developed countries, the authors know that the high positive value of $\mathrm{T}_{\text {LIVC }}$ indicates a better $\partial t$ in even dimensions $(2 \mathrm{~N})$. Among the total enterprises performance in China, USA, UK and Japan, The highest mutual interaction $\mathrm{T}_{\mathrm{LIVC}}$ (or synergy level) in USA means enterprises performance best in the with a series of increasing changes. That is to say, through the digital platform and system, the enterprises in USA combines the advanced digital technology with getting rid of physical locations bias. Those enterprises from different locations interactive relations is more closely in digital word with decreasing transaction cost, administration cost and etc. because of technology innovation application in recent years, the mutual interaction of enterprises in China has $\mathrm{T}_{\mathrm{LIVC}}$ as high as USA. Effective communication and knowledge sharing among enterprises in China are catching up with USA. China population bonus simulates the technologies innovation and its application in scene. At the same time, The feedback business data in the network give insights into advanced progress and artificially benefit business mode in improving management such as the smarter logistics between upstream suppliers and downstream sale agents with disappearing physical obstacle. They will be well-matched in strength and capability in the future. However, UK and Japan in peer level fall behind USA or China because of not capturing the technologies bonus. The enterprises such as supplies, agents, cooperation partners in distinct sits do not reconcile with each other well in UK and Japan. Their digital distance is still needed to be reduced in the future with the more digital application.

\section{CONCLUSIONS}

In the context of digital transformation, Shanghai is the most important city in China, with an area of 6,000 square kilometers, which is much larger than New York, London, Tokyo, Paris and other international metropolises. Shanghai has a core area that includes business developments(such as financial and other modern service industry clusters), its suburban areas contain traditional service industries, and its outer suburbs include advanced manufacturing industries, traditional manufacturing industries and the service industries. According to regional theory, industrial structure adjustment 
and industrial upgrade will continue in Shanghai because it is participating in the global value chain. The industry upgrade will also reflect the changes in industrial locations in the city, which follow differentiated land rents and laws of marginal revenue. However, this adjustment is inspired jointly by market and government forces. This study showed that enterprises interact with both vertical upstream and vertical downstream enterprises and move among the different locations in the pursuit of profit. However, in recent years, enterprise performance is characterized by larger fluctuations. Although the overall perspective the triple interactions among location, industry and vertical industrial linkages shows good performance, each of the two interaction variables remains uncertain. This finding shows that more technologies can be applied to optimize the infrastructural communication and computing services, to most effectively support distributed co-workers and the government should follow economic rules of thumb in its industrial policy and city space planning and play a more active role in promoting the spatial evolution of entire industries(so the layout of industry will work more efficiently); In this manner, Shanghai will enjoy more obvious competitive advantages than other international metropolises.

\section{FUNDING AGENCY}

This research was supported by National Natural Science Foundation of China(NSFC): Research on public health emergency response system and mechanisms based on the spatial diffusion law of pandemic(NO.72174117). 


\section{REFERENCES}

Abramson, N. (1963). Information Theory and Coding. McGraw-Hill.

Beltramello, A., De Backer, K., \& Moussiegt, L. (2012). The Export Performance of Countries within Global Value Chains (GVCs). OECD Science, Technology and Industry Working Papers.

Bitzer, J., Geishecker, I., \& Gorg, H. (2008). Productivity spillovers through vertical linkages: Evidence from 17 OECD countries. Economics Letters, 99(2), 328-331.

Bo, Z., \& Yu, B. O. (2010). Discussion on the innovation mode of the three spiral. Heilongjiang Social Sciences, $122(5), 35-38$.

Chatterjee, I. (2021). Artificial Intelligence and Patent ability: Review and Discussions. International Journal of Modern Research, 1, 15-21.

Chen, Y. (2012). Information Sharing Incentive Mechanism in Global Value Chain. 2012 IEEE Symposium on Robotics and Application(ISRA), 144-147.

Dhiman, G., \& Kaur, A. (2019). STOA: A bio-inspired based optimization algorithm for industrial engineering problems. Engineering Applications of Artificial Intelligence, 82, 148-174.

Dhiman, G., \& Kumar, V. (2017). Spotted hyena optimizer: A novel bio-inspired based meta heuristic technique for engineering applications. Advances in Engineering Software, 114, 48-70.

Dhiman, G., \& Kumar, V. (2018). Emperor penguin optimizer: A bio-inspired algorithm for engineering problems. Knowledge-Based Systems, 159, 20-50.

Duch, N. (2005). Vertical linkages, agglomeration and the organization of production in European regions. https://ideas.repec.org/p/ieb/wpaper/223533art101.html

Etzkowitz, H., \& Leydesdorff, L. (1995). The triple helix of university-industry -government relations: A laboratory for knowledge based economic development. EASST Review, (1), 14-19.

Fang, W. H. (2003). Triple Helix Model in Innovation Research:Concept,Structure and Public Policy Implication. Studies in Dialectics of Nature, 19(11), 69-72.

Gereffi, G. (2011). Global value chains and international competition. The Antitrust Bulletin, 56(1), 37-56.

Haakonsson, S. J. (2009). The Changing Governance Structures of the Global Pharmaceutical Value Chain. Competition \& Change, 13(1), 75-95. doi:10.1179/102452909X390574

Hua \& Wei. (2009). Triple helix interface organization and innovation mechanism. Science Research Management, $30(1), 15-21$.

Ivarssony, I., \& GoranAlvstam, C. (2011). Upgrading in global value-chains: A case study of technology-learning among IKEA-suppliers in China and Southeast Asia. Journal of Economic Geography, 11(4), 731-752.

Jabbour, L., \& Moucchielli, J. L. (2007). Technology transfer through vertical linkages: The case of the spanish manufacturing. International Journal of Applied Economics, 10(1), 115-136.

Ji, F. H. (2007). China's foreign direct investment industry location matrix model. Research on Productivity, $18,106-108$.

Jian, L. (2011). Pesticide industry agglomeration and industrial growth in China. Jiangsu agricultural science and technology, 39(2), 517-519.

Jun, T., \& Wu, G. S. (2006). An introduction of the Triple Helix Model and its application in China. Science Research Management, 27(3), 75-80.

Kaur, S., Awasthi, L. K., Sangal, A. L., \& Dhiman, G. (2020). Tunicate Swarm Algorithm: A new bio-inspired based metaheuristic paradigm for global optimization. Engineering Applications of Artificial Intelligence, 90, 103541.

Kiyota, K. (2008). Reconsidering the Backward Vertical Linkages of Foreign Affliates: Evidence from Japanese Multinationals. World Development, 36(8), 1398-1414. 
Kumar, R., \& Dhiman, G. (2021). A Comparative Study of Fuzzy Optimization through Fuzzy Number. International Journal of Modern Research, 1, 1-14.

Lengyel, B., \& Leydesdorff, L. (2011). Regional innovation systems in Hungary: The failing synergy at the national level. Regional Studies, 45(5), 677-693. doi:10.1080/00343401003614274

Leydesdorff, L. (2002). The Measurement and Evaluation of Triple Helix Relations among Universities, Industries and Governments. https://www.leydesdorff.net/th4

Leydesdorff, L., \& Curran, M. (2000). Mapping University-Industry-Government Relations on the Internet: An Exploration of Indicators for a Knowledge-Based Economy. https://www.leydesdorff.net/list90s.htm

Leydesdorff, L., \& Fritsch, M. (2006). Measuring the Knowledge Base of Regional Innovation Systems in Germany in terms of a Triple Helix Dynamics. Research Policy, 35(10), 1538-1553. doi:10.1016/j.respol.2006.09.027

Leydesdorff, L., \& Fritsch, M. (2006). Measuring the knowledge base of regional innovation systems in Germany in terms of a triple helix dynamics. Research Policy, 35(10), 1538-1553. doi:10.1016/j.respol.2006.09.027

Liu, X., Wang, C., \& Wei, Y. (2009). Do Local Manufacturing Firms Benefit from Transactional Linkages with Multinational Enterprises in China. Palgrave Macmillan Journals, 40(7), 1113-1130.

Liu, Y. F., Peng, X. M., \& Peng, X. J. (2007). Construction of China's entrepreneurial university innovation based on the theory of the three helix model. Science \& Technology Progress and Policy, 24(11), 106-108.

Mariotti, S., Nicolini, M., \& Piscitello, L. (2013). Vertical linkages between foreign MNEs in service sectors and local manufacturing firms. Structural Change and Economic Dynamics, 25, 133-145.

Niu, P. Q., Fu Ji, X., \& Fu Ming, Z. (2009). Measuring the Knowledge Base of Economy of Province in China. Journal of Systems \& Management, 18(5), 1005-2542.

Nu, P. Q., \& Xie, F. J. (2009). Recent Research Development of Innovation Triple Helix. $R \&$ \& Management, 21(5), 94-100.

Pan, D. H., \& Da Wei, Y. (2008). Triple helix interface organization and knowledge transfer in the innovation. Studies in Science of Science, 26(5), 1073-1079.

Ping, L., \& Saggi, K. (2007). Multinational firms, exclusivity, and backward linkages. Journal of International Economics, 71(1), 206-220.

Qi, S. H., \& Si, W. (2007). Analysis of Chinese innovation strategy evolution and trend based on the three helix mode. China Technology Forum, 7, 3-6.

Qi, S. H., \& Si, W. (2007). Analysis of Chinese innovation strategy evolution and trend based on the three helix model. China Technology Forum, 7, 3-6.

Shannon, C. E. (1948). A Mathematical Theory of Communication. The Bell System Technical Journal, 27(3), 379-423, 623-656. doi:10.1002/j.1538-7305.1948.tb01338.x

Shao, Y. J., Li, J. P., \& Zhou, Z. Y. (2010). Analysis of Dynamic Variation of Henan Province's Wheat Industry Location Modulus. Chinese Technology Forum, 12(5), 135-141.

Shuo, W., \& Guo, X. X. (2012). Vertical Linkage, Industry Interaction and Double Agglomeration. Financial Science, 9, 34-41.

Storper, M. (1997). The regional world-territorial development in a global economy. Guilford Press.

Theil, H. (1972). Statistical Decomposition Analysis. North-Holland.

Tie, W. (2012). Research on Development of Guang xi Industries Based on Region Entropy and Gray Model Analysis. Value Engineering, 31(1), 7-8.

Vaishnav, P. K., Sharma, S., \& Sharma, P. (2021). Analytical Review Analysis for Screening COVID-19. International Journal of Modern Research, 1, 22-27.

Vaishnav, P. K., Sharma, S., \& Sharma, P. (2021). Analytical Review Analysis for Screening COVID-19. International Journal of Modern Research, 1, 22-27. 
Wang, C. J. (2006). Comparative researches on measurement based triple helix of university- industry-government partnerships. Science Research Management, 27(6), 19-26.

Wang, R. D. (2008). Triple helix Based Research on the Creativity City:Case Study of Su Zhou Industrial Park. Public Management, 5, 78-81.

Wang, Y. (2010). FDI and productivity growth: The role of inter-industry linkages. The Canadian Journal of Economics. Revue Canadienne d'Economique, 43(4), 1243-1272.

Xiang, Wang, \& Li. (2010). Contribution and Problems of Triple Helix Innovation Theory and the Implications for China. Research on Economic and Management, 1, 26-29.

Xu \& Luo. (2008). Multimedia Industry's Distribution and Enterprises' Location Decision-making in Shanghai. Research and Development of the Region, 27(1), 28-31.

Zhang, X. P., Chi, J. M., \& Hu, X. L. (2010). The Innovation of Entrepreneurial University Management Model Based on the Triple Helix Theory. University Education Science, 123(5), 43-47.

Zheng, S., Chang, P.-Y., Chen, J., Chang, Y.-W., \& Fan, H.-C. (2021). An Investigation of Patient Decisions to Use eHealth: A View of Multichannel Services. Journal of Organizational and End User Computing, 34(4), 1-24. doi:10.4018/JOEUC.289433

Zhou, L. H. (2011). Agglomeration on within Industry, Vertical Spillovers Related Industries and Enterprises Efficiency- Based on Panel Data of Manufacturing Enterprises in Guangdong Province. Journal of Lanzhou Commercial College, 27(2), 77-83.

Zhou \& Etzkowitz. (2006). Triple Helix Twins: Innovation and Sustainability. Journal of Northeastern University (Social Science), 8(3), 170-174.

Zhou \& Etzkowitz. (2008). Theoretical Exploration on Triple Helix Based on Non-linear and Netlike Innovation Model. Journal of Northeastern University (Social Science), 10(4), 300-304.

Zou, L. (2010). Technological capabilities and local firms upgrading within global value chains. Management and Service Science, 1-4. 